This is the authors' version of the manuscript that was accepted for publication.

Full citation details of the published article are: Saxton, T. K., Steel, C., Rowley, K., Newman, A.V., \& Baguley, T. (in press). Facial resemblance between women's partners and brothers. Evolution and Human Behavior. doi: http://doi.org/10.1016/j.evolhumbehav.2017.04.006

\title{
1 Facial resemblance between women's partners and brothers
}

2

3 Tamsin K. Saxton*a, Catherine Steel ${ }^{a}$, Katie Rowleya , Amy V. Newman ${ }^{a}$, Thom Baguley ${ }^{b}$.

4

$5 \quad$ * corresponding author. tamsin.saxton@northumbria.ac.uk. +44(0)191227 4486.

6

7 a Evolution, Perception \& Behaviour Research Group, Psychology Department, Northumbria University, Northumberland Building, Ellison Place, Newcastle, NE1 8ST.

9

${ }^{b}$ Department of Psychology, School of Social Sciences, Nottingham Trent University, 50 Shakespeare Street, Nottingham NG1 4FQ.

\section{Abstract}

Research on optimal outbreeding describes the greater reproductive success experienced on average by couples who are neither too closely related, nor too genetically dissimilar. How is optimal outbreeding achieved? Faces that subtly resemble family members could present useful cues to a potential reproductive partner with an optimal level of genetic dissimilarity. Here, we present the first empirical data that heterosexual women select partners who resemble their brothers. Raters ranked the facial similarity between a woman's male partner, and that woman's brother compared to foils. In a multilevel ordinal logistic regression that modeled variability in both the stimuli and the raters, there was clear evidence for perceptual similarity in facial photographs of a woman's partner and her brother. That is, although siblings themselves are sexually aversive, sibling resemblance is not. The affective responses of disgust and attraction may be calibrated to distinguish close kin from individuals with some genetic dissimilarity during partner choice. 


\section{Introduction}

In selecting a partner, the most reproductively successful individuals are those that avoid partners who are too closely or too distantly related, thereby avoiding both inbreeding and outbreeding (see e.g. Edmands 2007). Inbreeding is biologically detrimental due to the accumulation of harmful recessive genes, a reduction in useful genetic heterozygosity, the possibility of increased competitiveness between similar offspring, and a reduction in offspring variability (Bateson 1983). Excessive outbreeding, on the other hand, may separate genes that work well together, disrupt the inheritance of traits that have been adapted to work well in the local environment, and increase the costs of altruism (Bateson 1983; Rushton 1989). Empirical data that support the value of intermediate relatedness ('optimal outbreeding') have been presented for many species, including humans. For example, a study of all known couples born in Iceland during a 165-year period found that the optimal level of relatedness in that population in terms of number of grandchildren was around the level of third or fourth cousin (Helgason, et al. 2008).

How do people avoid both inbreeding and excessive outbreeding? The avoidance of inbreeding appears to be operationalised by the Westermarck effect, whereby people are not sexually attracted to those with whom they socialise during childhood (reviewed in Rantala and Marcinkowska 2011). An aversion to siblings as sexual partners seems to develop through maternal perinatal association and coresidence duration (De Smet, et al. 2014; Lieberman 2009; Lieberman, et al. 2007). To avoid excessive outbreeding however, slight physical resemblance might provide an appropriate cue. Features found in parental faces might be one of the most useful cues to genetic similarity, particularly in the environment in which humans evolved, without frequent exposure to views of themselves in reflective surfaces. Data support this: several studies have found that people choose partners and prefer faces that resemble their parents (Bereczkei, et al. 2002; Bereczkei, et al. 2004; Dixson, et al. 2013; Heffernan and Fraley 2013; Jedlicka 1980; Jedlicka 1984; Little, et al. 2003; Marcinkowska and Rantala 2012; Perrett, et al. 2002; Rantala, et al. 2010; Saxton 2016; Seki, et al. 2012; Wilson and Barrett 1987; Zei, et al. 1981); see also (Fraley and Marks 2010; Rantala and Marcinkowska 2011); but see (Nojo, et al. 2011).

However, parental appearance is an incomplete source of information. Maternal appearance provides just one point of reference. Reliance on paternal faces is potentially problematic: serial relationships in 
both traditional (Hill and Hurtado 1996) and modern societies (Cherlin 1981) mean that the father might no longer be present. In addition, the putative father is not the biological father in cases that may average around $2 \%$ of births worldwide (see Bressan and Kramer 2015). Sibling facial features therefore could be a useful point of reference, especially given the extensive presence of siblings during an individual's childhood in historically high-fertility populations. Additionally, younger brothers are more readily detected as kin than older brothers (Lieberman, et al. 2007), and thus might be the better referent for kin resemblance. Accordingly, our study used a multilevel ordinal logistic regression analysis to investigate resemblance between a woman's partner and her brother, alongside the possible moderating effects of absolute and relative age, in two separate samples.

\section{Material and Methods}

All of the research described herein was granted ethical approval by the Northumbria University Psychology Department Ethics Committee.

\subsection{Stimuli creation}

Stimuli were obtained in two ways: through the provision of photographic images by consenting individuals ('volunteer sample'), and by the collection of appropriate photographic images available online ('online sample'). The volunteer sample consisted of 32 female participants who passed on details of the study to their brother and male partner, who in turn supplied photographs of themselves. The 32 brothers (aged 18 - 40; mean +/- SD = 24 +/- 5 years) and 32 partners (aged $20-37$; mean +/$\mathrm{SD}=23+/-4$ years) were requested to provide good quality, recent, colour facial photographs, with a neutral facial expression, although participants were often smiling in the photographs that they supplied. The online sample consisted of 48 photographs (24 brothers, 24 partners) that were located online by a researcher (A.N.) who had been instructed to find relatively recent facial photographs of brothers and partners of public figures or celebrities. All individuals in the photographs were aged 18 or over, and exact ages were identified for all but two of the siblings; 22 of the brothers were aged $21-53$ (mean $+/-\mathrm{SD}=31+/-8$ years), and the 24 partners were aged $22-50$ (mean $+/-\mathrm{SD}=34+/-9$ years). The researcher was asked to find brothers and partners who appeared to be of white ethnicity, where the face of a single individual was apparent with a fairly neutral facial expression and unadorned features (i.e. without glasses, make-up, etc.) The photographs had to be sourced from a site that allowed the 
usage of photographs in research (i.e. non-commercially), and the photographs had to be taken in a venue where the individual in the photograph could reasonably expect to be observed by strangers, following ethical guidelines for the research use of information available online (Hewson and Buchanan 2013). Across the whole sample, 28 of the brothers were older than the woman whose partner's photograph was in the study, and 28 of the brothers were younger (or, in one instance, a twin, who was categorised here as a younger brother). Three of the men had features consistent with Asian ethnicity, while all of the others appeared to be of white ethnicity. We performed an additional check of our statistical model by adding a categorical term to distinguish these three men along with one man who was a half brother, but found no significant effect.

The photographs were grouped into sets of four brothers and four partners, keeping separate the volunteer and online sample to increase within-set consistency in photograph quality and cultural or demographic variables. The photographs were grouped so that six of the sets only contained younger brothers, six of the sets only contained older brothers, and two of the sets (one from the volunteer sample and one from the online sample) contained a mixture (3:1) of younger and older brothers. The photographs were arranged into tableaux following the methodology of previous work on preferences for parental resemblance in faces (Bereczkei, et al. 2002; Bereczkei, et al. 2004), and printed in colour on A4 sheets of paper. Photographs varied a little in size, but each was around $5 \mathrm{~cm} \times 6 \mathrm{~cm}$. Photographs were cropped to focus in on the face, so typically would be cropped from just below the chin to just above the top of the hair. On the right-hand side, the four photographs of the four partners in a set were displayed; this set of four photographs was repeated identically across four sheets of paper. On the lefthand side of these four sheets, the photograph of one of the brothers from the same set was displayed, with a different brother on each of the four sheets. In addition, four versions of each of the two tableaux that contained a mixture of older and younger brothers were created, so that the placement on the stimulus sheet of the photograph of the single younger/older brother could be fully counterbalanced in the four possible positions (top/bottom left/right). After these constraints, the selection of photographs for each set was based on ordered partner age from youngest to oldest, so that the people in the photographs were as similar as possible in age. The age difference between the oldest and youngest of the four partners in each set ranged from 0 to 16 years, with a mean age difference of 5 years 
114 between the oldest and youngest partner in each set. Age and relative age (older or younger) were

115 included as variables in the models (see below).

\subsection{Photograph rating}

118 An opportunity sample of 32 female raters aged 19 to 40 (mean $+/$ - SD $=24+/-5$ years) were presented with the 56 tableaux in random order. Female raters were chosen because the volunteer and online sample were all female, and so we wanted to focus on female facial perception. For each tableau, they were asked to rank the four men on the right hand side (the partner plus three foils) in terms of their similarity to the man on the left hand side (the brother). A sample size of 32 raters was selected based on pilot work (see Supplementary Online Material 2). Raters were not told that the individuals in the photographs were related, but only that the study was investigating perceptions of facial similarity. Participants were quizzed and debriefed afterwards, and no-one reported guessing the aims of the study. 23 out of a possible 1792 of the raters' responses (1.3\%) were unclear (e.g. a rater listed the same photo as both most and third most similar) and these were treated as missing data in the model. Data were collected from one additional rater, but were discarded prior to analysis because the tableaux were erroneously provided in numerical rather than randomised order, meaning that the same image of the same four brothers was presented on the right-hand side of all of the first four tableaux, then the same four brothers were presented on the second four tableaux, and so on.

\section{Results}

134 Rating data were modelled using multilevel ordinal logistic regression implemented in the ordinal package (Christensen 2015) within R (http://www.R-project.org/). Using an ordinal model permitted us to model the cumulative probability of the brother and partner being ranked as 1) most similar to each other; 2) most or second most similar; and 3) most, second most or third most similar. The advantage of a multilevel model is that variability in both faces and raters can be incorporated into the model as fully crossed random effects. Traditional analyses that ignore variability in either faces or raters, either by treating ratings as independent or by modelling variability by raters or by faces in isolation, are known to inflate Type I error (see e.g. Baguley 2012; Judd, et al. 2012). Our initial model therefore included two random effects (face and rater) and three intercepts representing the thresholds in the ordinal 
logistic regression model on a log odds scale. In this intercept-only model, the estimate of face variability is 1.251 while the rater variability is negligible $\left(1.7 \times 10^{-5}\right)$ suggesting individual differences in the resemblance of brothers to partners, but near independence of rankings within raters in our sample. The estimated thresholds for the ratings were $-1.02,0.34$ and 1.67 corresponding to a cumulative probability of $.27, .59$ and .84 . The raters were choosing from four photos, and so if they were picking at chance levels, they should have chosen the correct pair at a rate of .25 . The probability of ranking the brother most (.27), second (.32), or third (.26) most similar to the partner therefore appears elevated relative to chance $(.25)$, while the probability of ranking the brother least similar to the partner is depressed (.16) (Figure 1).

152

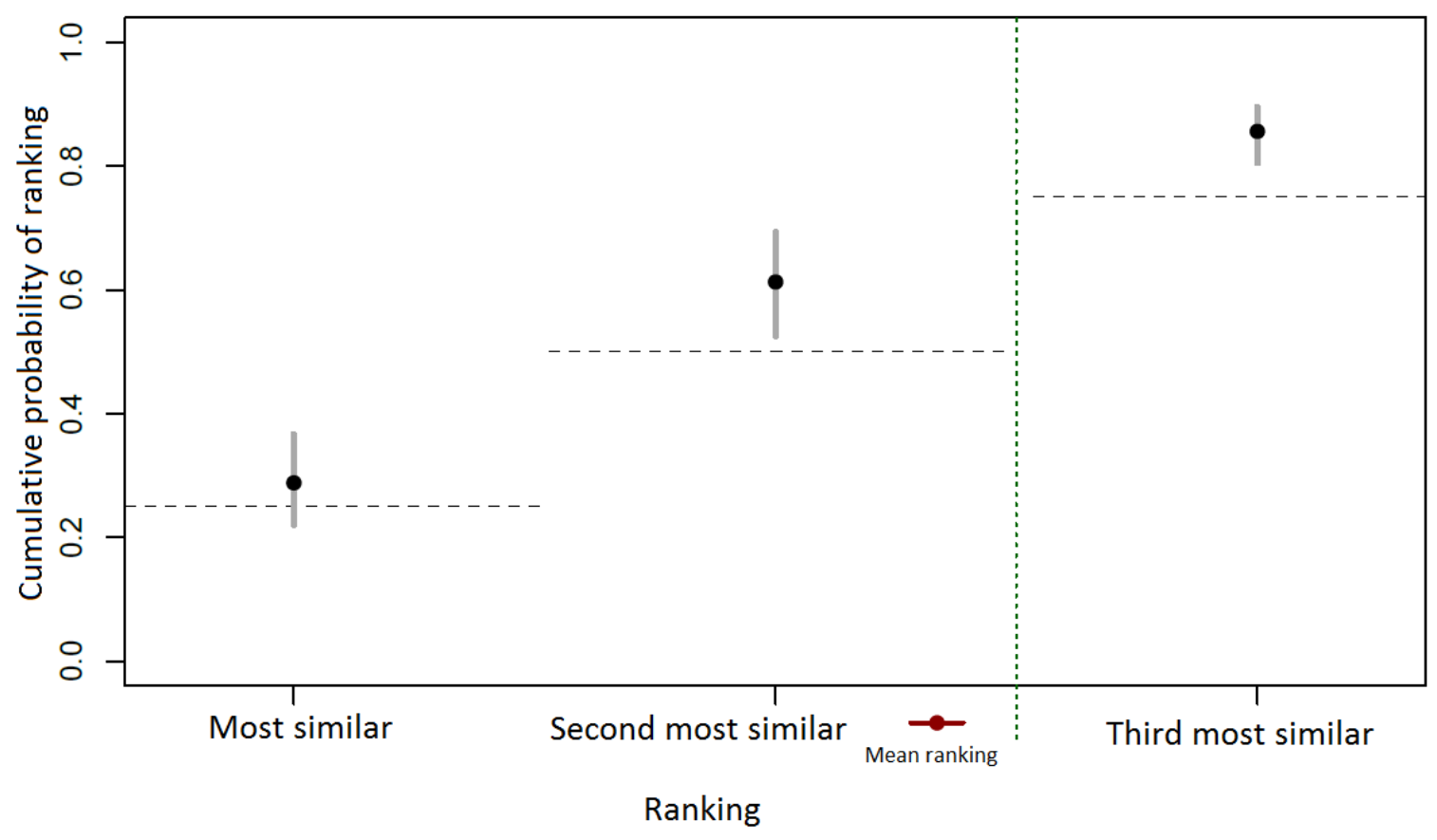

Figure 1: Cumulative probability of ranking the correct brother-boyfriend pairing as most, second most, and third most similar, while controlling for participant age and sample source (see section 2 Materials and Methods and section 3 Results). Observed values (mean $+/-95 \% \mathrm{Cls}$ ) are indicated by solid vertical lines, while chance values for each ranking are marked by dashed horizontal lines. $A$ 95\% $\mathrm{Cl}$ for the mean rankings are indicated as calculated using the intercept-only model (red horizontal line) and under the null hypothesis of equiprobability (vertical dotted line). 
162 To test whether the joint pattern of ratings was consistent with guessing we simulated a $95 \% \mathrm{Cl}$ for the mean rating by parametric bootstrapping of the intercept only model (incorporating the random effects of both faces and raters). This simulation (with 5000 replicated data sets) estimated the mean ranking as $2.335,95 \% \mathrm{Cl}[2.28,2.39]$ and close to the observed mean ranking of 2.338 (to 3 d.p.). The potential impact of missing data (1.3\% of the expected total data; see subsection 2.2 Photograph rating) was simulated by replacing simulated data with missing values with a fixed probability equal to that observed in the real data set. This is equivalent to treating data as missing completely at random (though with so few missing cases the impact on inferences is neglible). A null hypothesis test of the observed mean ranking was obtained by simulating an equiprobability model (fixing the probability of each ranking at 0.25 ) with the same random effects. Under the equiprobability model the mean ranking was 2.50 ( $S E=$ 0.0287 ) and not consistent with the observed mean of $2.34, z=5.64, p<.0001$.

A further model was fitted to determine the influence of other variables on the rankings. This model included the woman's age (centred) as a continuous predictor, and several categorical predictors: brother's relative age (older or younger), partner's relative age (older or younger), and whether the photo came from the volunteer sample or the online sample. All categorical predictors were effect coded for this analysis and effects were tested by a likelihood ratio test. Only partner's relative age was close to statistical significance, $G^{2}(1)=2.76, p<.10$ (with other effects $G^{2}<1$ ). There is thus little evidence that any of these variables influenced the ratings. Including these predictors also had little impact on the thresholds; Figure 1 shows the cumulative probability of rating the sibling as most, second most or third most similar when these predictors were included. Although stimuli were counterbalanced we also checked the impact of tableaux version and position of the correct match by including version, position and all version by position interactions. None of the effects reached statistical significance and the overall change in fit was negligible, $G^{2}(15)=10.2, p=.81$. As a final check we tested the hypothesis that ratings were driven merely by the similarity or dissimilarity in age of the partners and brothers or of the women and their brothers. To this end we added the absolute difference in ages to the model for each of these comparisons; neither was close to statistical significance, $G^{2}<1$.

\section{Discussion}


191 We present clear evidence that women select partners who resemble their brothers. This is true 192 irrespective of whether the sample is based around a student or a celebrity population. People 193 experience strong aversion and disgust towards incest (Antfolk, et al. 2012). However, identity is not the same as resemblance; the proper domain of kinship detecting mechanisms (Lieberman, et al. 2007) might entail the creation of aversion to siblings themselves, and not to those that resemble them. Our results suggest that affective responses during partner choice (disgust and attraction) could be calibrated to distinguish actual close kin from those who might be somewhat genetically similar and could thereby support optimum outbreeding. That is, people are disgusted by thinking about engaging in relationships with siblings (Lieberman, et al. 2007), but seem to pick partners who show some slight resemblance to siblings.

Facial resemblance can indicate relatedness even beyond immediate family members (Davidson 1993; Kaminski, et al. 2009). Although contextual cues such as kinship nomenclature and family histories also indicate relatedness, automated cue-based processes might function alongside and independently of explicit knowledge, and have a deeper evolutionary history (Park, et al. 2008). Humans can detect kinship on the basis of appearance similarity in mother-daughter pairs in mandrills, gorillas, chimpanzees and macaques (Alvergne, et al. 2009; Vokey, et al. 2004). Non-human primates can also detect visual similarity in kin (e.g. Kazem and Widdig 2013; Parr and de Waal 1999; Pfefferle, et al. 2014). For much of human history, a preference for partners who demonstrated subtle resemblances to close family members might have supported the selection of a reproductive partner who was neither too closely nor too distantly related.

212

213 Facial cues to kinship play a role in sexual, parental and social behaviours (Lewis 2011; Park, et al. 214 2008). People are more likely to trust and invest in those whose familiar facial appearance indicates 215 possible family membership (DeBruine 2005; Platek, et al. 2002). As attraction affects every level of interpersonal interaction, our results also suggest a possible mechanism by which nepotism could be

217 scaffolded. Although we focussed on women's choices, the same tendencies should apply to men. Indeed, men might find sibling-resemblance less aversive than women do (Marcinkowska, et al. 2013), and this can be explained by men's lesser reproductive investment and hence lower risk in a suboptimal partner (Haig 1999). 
222 Siblings resemble parents, and individuals have been previously shown to select partners who resemble 223 their parents. Our work suggests that the effect sizes for each are similar (see Supplementary Material 224 1); parents and siblings could both provide reference points. Zebra finches (Kruijt, et al. 1983), snow geese (e.g. Cooke, et al. 1976; Cooke and McNally 1975; Walter 1973), bullfinch (Nicolai 1956), and mallards (Klint 1978) demonstrate preferences for sibling characteristics that are independent of preferences for parental characteristics. Siblings might provide a source of information on familial resemblance that is more extensive than that provided by parents. Future research should contrast parental, sibling and self resemblance explicitly, in order to parse their contributions to partner choice.

Previous research that has looked at the effects of siblings on attractiveness judgements of facial images does not support the interpretation that sibling resemblance unambiguously enhances judgements of attractiveness per se. One previous research study investigated the impact of siblingresemblance on attraction by computer-manipulating facial images so that they resembled the raters' siblings or the raters themselves. The study found that men rated sibling-resembling faces as significantly more attractive than self-resembling faces but not significantly different from control faces, whereas women rated sibling-resembling faces as significantly less attractive than control faces and no different from self-resembling faces (Marcinkowska, et al. 2013). Men with sisters have been found to be less likely to judge feminised women's faces attractive than men without sisters do (Marcinkowska, et al. 2016), although in contrast, adolescent boys in a single-sex school environment (i.e. with limited daytime visual exposure to girls) have been found to judge female facial femininity as more attractive if they have sisters than if they do not (Saxton, et al. 2009). Attractiveness judgements assessed in a laboratory context may not always map directly onto patterns of relationship formation and maintenance when other factors come into play.

246 One limitation of our study was that the photographs were not fully standardised; they portrayed facial 247 features, but also facial expressions, hairstyles, and some elements of clothing and background. We reduced the possible impact of these elements as much as possible by asking participants to provide standardised photographs, by cropping photographs to focus on the face, and by presenting the raters with photographs from the online sample separately from the volunteer sample (see Material and 
Methods section). We asked the raters to judge facial similarity, but these non-standardised elements likely contributed somewhat to their decisions. Therefore, it is possible that our raters were not matching the photographs merely on facial structural similarity, but also on elements such as emotionality (perceived through facial expressions), and socio-economic status and cultural cues (perceived through clothing and hairstyle). Nevertheless, we note that previous research that used non-standardised photographs (Bereczkei, et al. 2002; Bereczkei, et al. 2004) to examine similarity between individuals' partners and their parents revealed similar results to research that used standardised photographs (Vukovic, et al. 2015). Future research might undertake the logistically more complicated step of creating standardised photographs of all participants.

Our study focussed on contemporary western populations. Although our biologically-based hypotheses should apply cross-culturally, other cultures remain to be tested. Indeed, we found substantive interindividual variability in the extent to which a woman's brother and partner were similar: not all women select partners who resemble their brothers. Accordingly, the effect will be weaker in contexts that amplify the variables that reduce preferences for brother-resemblance. We did not find that older compared to younger brothers had differential effects. Future research might investigate other possible individual predictors of brother-partner similarity, such as emotional closeness between brother and sister (Bereczkei, et al. 2002; Bereczkei, et al. 2004). However, here we demonstrate perceptual similarity between women's brothers and partners in a contemporary population.

Data Availability: The data associated with this research are available in the Supplementary Online Materials 3.

This research did not receive any specific grant from funding agencies in the public, commercial, or notfor-profit sectors.

\section{References}

Alvergne A, Huchard E, Caillaud D, Charpentier MJE, Setchell JM, Ruppli C, Féjan D, Martinez L, Cowlishaw G, Raymond M. 2009. Human ability to recognize kin visually within primates. International Journal of Primatology 30(1):199-210. D0I: 10.1007/s10764-009-9339-0 
Antfolk J, Karlsson M, Bäckström A, Santtila P. 2012. Disgust elicited by third-party incest: the roles of biological relatedness, co-residence, and family relationship. Evol. Hum. Behav. 33(3):217223. D0I: http://dx.doi.org/10.1016/i.evolhumbehav.2011.09.005

Baguley T. 2012. Serious Stats: A guide to advanced statistics for the behavioral sciences. Basingstoke: Palgrave.

Bateson P. 1983. Chapter 11: Optimal outbreeding. In: Bateson P, editor. Mate Choice. Cambridge: Cambridge University Press. p 257-

Bereczkei T, Gyuris P, Koves P, Bernath L. 2002. Homogamy, genetic similarity, and imprinting; parental influence on mate choice preferences. Pers. Indiv. Differ. 33(5):677-690. D0I:

Bereczkei T, Gyuris P, Weisfeld GE. 2004. Sexual imprinting in human mate choice. Proceedings of the Royal Society of London, Series B: Biological Sciences 271(1544):1129-1134. D0I:

Bressan P, Kramer P. 2015. Human kin detection. Wiley Interdisciplinary Reviews: Cognitive Science 6(3):299-311. D0I: 10.1002/wcs.1347

Cherlin AJ. 1981. Marriage, Divorce, Remarriage: Social trends in the United States. Cambridge, Massachusetts: Harvard University Press.

Christensen RHB. 2015. ordinal - Regression models for ordinal data. R package version 2015.1-21.

Cooke F, Finney GH, Rockwell RF. 1976. Assortative mating in lesser snow geese (Anser caerulescens). Behav. Genet. 6(2):127-140. D0I: 10.1007/bf01067143

Cooke F, McNally CM. 1975. Mate selection and colour preferences in lesser snow geese. Behaviour 53(1):151-169. D0l: doi:http://dx.doi.org/10.1163/156853975X00588

Davidson HR. 1993. A large family with patent ductus arteriosus and unusual face. J. Med. Genet. 30(6):503-505. D0I: 10.1136/jmg.30.6.503

De Smet D, Van Speybroeck L, Verplaetse J. 2014. The Westermarck effect revisited: a psychophysiological study of sibling incest aversion in young female adults. Evol. Hum. Behav. 35(1):34-42. D0I: http://dx.doi.org/10.1016/j.evolhumbehav.2013.09.004

DeBruine LM. 2005. Trustworthy but not lust-worthy: context-specific effects of facial resemblance. Proc. Biol. Sci. 272(1566):919-922. D0I:

Dixson BJ, Tam JC, Awasthy M. 2013. Do women's preferences for men's facial hair change with reproductive status? Behav. Ecol. 24(3):708-716. D0l: 10.1093/beheco/ars211 
Edmands S. 2007. Between a rock and a hard place: evaluating the relative risks of inbreeding and outbreeding for conservation and management. Mol. Ecol. 16(3):463-475. D0I: 10.1111/j.1365-294X.2006.03148.x

Fraley RC, Marks MJ. 2010. Westermarck, Freud, and the incest taboo: Does familial resemblance activate sexual attraction? Pers. Soc. Psychol. B. 36(9):1202-1212. D0l: $10.1177 / 0146167210377180$

Haig D. 1999. Asymmetric relations: Internal conflicts and the horror of incest. Evol. Hum. Behav. 20(2):83-98. D0I: http://dx.doi.org/10.1016/S1090-5138(98)00042-7

Heffernan ME, Fraley RC. 2013. Do early caregiving experiences shape what people find attractive in adulthood? Evidence from a study on parental age. Journal of Research in Personality 47(4):364-368. D0I: 10.1016/j.jrp.2013.03.003

Helgason A, Pálsson S, Guðbjartsson DF, Kristjánsson p, Stefánsson K. 2008. An association between the kinship and fertility of human couples. Science 319(5864):813-816. D0I: 10.1126/science. 1150232

Hewson C, Buchanan T. 2013. Ethics Guidelines for Internet-mediated Research. Leicester, UK: British Psychological Society

Hill K, Hurtado AM. 1996. Ache Life History: The ecology and demography of a foraging people. New York: Aldine de Gruyter.

Jedlicka D. 1980. A test of the psychoanalytic theory of mate selection. J. Soc. Psychol. 112(2):295. D0I:

Jedlicka D. 1984. Indirect parental influence on mate choice: A test of the psychoanalytic theory. Journal of Marriage and Family 46(1):65-70. D0I: 10.2307/351864

Judd CM, Westfall J, Kenny DA. 2012. Treating stimuli as a random factor in social psychology: A new and comprehensive solution to a pervasive but largely ignored problem. J. Pers. Soc. Psychol. 103(1):54-69. D0I:

Kaminski Gl, Dridi S, Graff C, Gentaz E. 2009. Human ability to detect kinship in strangers' faces: effects of the degree of relatedness. Proc. Biol. Sci. 276(1670):3193-3200. D0I: $10.1098 / \mathrm{rspb} .2009 .0677$

Kazem AJN, Widdig A. 2013. Visual phenotype matching: Cues to paternity are present in rhesus macaque faces. PLOS ONE 8(2):e55846. D0I: 10.1371/journal.pone.0055846 
Klint T. 1978. Significance of Mother and Sibling Experience for Mating Preferences in the Mallard (Anas platyrhynchos). Z. Tierpsychol. 47(1):50-60. D0I: 10.1111/j.1439-0310.1978.tb01822.x

Kruijt JP, Ten Cate CJ, Meeuwissen GB. 1983. The influence of siblings on the development of sexual preferences of male zebra finches. Dev. Psychobiol. 16(3):233-239. D0I: $10.1002 / \operatorname{dev} .420160309$

Lewis DMG. 2011. The sibling uncertainty hypothesis: Facial resemblance as a sibling recognition cue. Pers. Indiv. Differ. 51(8):969-974. D0I: http://dx.doi.org/10.1016/i.paid.2011.08.002

Lieberman D. 2009. Rethinking the Taiwanese minor marriage data: evidence the mind uses multiple kinship cues to regulate inbreeding avoidance. Evol. Hum. Behav. 30(3):153-160. D0I: http://dx.doi.org/10.1016/j.evolhumbehav.2008.11.003

Lieberman D, Tooby J, Cosmides L. 2007. The architecture of human kin detection. Nature 445(7129):727-731. D0I: http://www.nature.com/nature/journal/v445/n7129/suppinfo/nature05510 S1.html

Little AC, Penton-Voak IS, Burt DM, Perrett DI. 2003. Investigating an imprinting-like phenomenon in humans: Partners and opposite-sex parents have similar hair and eye colour. Evol. Hum. Behav. 24(1):43. D0I:

Marcinkowska UM, Moore FR, Rantala MJ. 2013. An experimental test of the Westermarck effect: sex differences in inbreeding avoidance. Behav. Ecol. 24(4):842-845. D0I: 10.1093/beheco/art028

Marcinkowska UM, Rantala MJ. 2012. Sexual imprinting on facial traits of opposite-sex parents in humans. Evolutionary Psychology 10(3):621-630. D0I:

Marcinkowska UM, Terraube J, Kaminski G. 2016. Imprinting and flexibility in human face cognition. Scientific Reports 6:33545. D0I: 10.1038/srep33545

Nicolai J. 1956. Zur Biologie und Ethologie des Gimpels (Pyrrhula pyrrhula L.) D. 77. Z. Tierpsychol. 13(1):93-132. D0I: 10.1111/j.1439-0310.1956.tb01549.x

Nojo S, Ihara Y, Furusawa H, Akamatsu S, Ishida T. 2011. Facial resemblance and attractiveness: an experimental study in rural Indonesia. Letters on Evolutionary Behavioral Science 2(1):9-12. D0I:

Park JH, Schaller M, Van Vugt M. 2008. Psychology of human kin recognition: Heuristic cues, erroneous inferences, and their implications. Rev. Gen. Psychol. 12(3):215-235. D0l: $10.1037 / 1089-2680.12 .3 .215$ 
Parr LA, de Waal FBM. 1999. Visual kin recognition in chimpanzees. Nature 399(6737):647-648. D0I:

Perrett DI, Penton-Voak IS, Little AC, Tiddeman BP, Burt DM, Schmidt N, Oxley R, Kinloch N, Barrett L. 2002. Facial attractiveness judgements reflect learning of parental age characteristics. Proceedings of the Royal Society of London - Biological Sciences (Series B) 269(1494):873880. D0I: $10.1098 / \mathrm{rspb} .2002 .1971$

Pfefferle D, Kazem Anahita JN, Brockhausen Ralf R, Ruiz-Lambides Angelina V, Widdig A. 2014. Monkeys spontaneously discriminate their unfamiliar paternal kin under natural conditions using facial cues. Curr. Biol. 24(15):1806-1810. D0I: http://dx.doi.org/10.1016/j.cub.2014.06.058

Platek SM, Burch RL, Panyavin IS, Wasserman BH, Gallup JGG. 2002. Reactions to children's faces: Resemblance affects males more than females. Evol. Hum. Behav. 23(3):159. D0I:

Rantala M, Marcinkowska U. 2011. The role of sexual imprinting and the Westermarck effect in mate choice in humans. Behav. Ecol. Sociobiol. 65(5):859-873. D0I: 10.1007/s00265-011-1145-y

Rantala MJ, Polkki M, Rantala LM. 2010. Preference for human male body hair changes across the menstrual cycle and menopause. Behav. Ecol. 21(2):419-423. D0I: 10.1093/beheco/arp206

Rushton JP. 1989. Genetic similarity, human altruism, and group selection. Behav. Brain Sci. 12(03):503-518. D0I: doi:10.1017/S0140525X00057320

Saxton TK. 2016. Experiences during specific developmental stages influence face preferences. Evol. Hum. Behav. 37(1):21-28. D0I: http://dx.doi.org/10.1016/j.evolhumbehav.2015.06.001

Saxton TK, Little AC, DeBruine LM, Jones BC, Roberts SC. 2009. Adolescents' preferences for sexual dimorphism are influenced by relative exposure to male and female faces. Pers. Indiv. Differ. 47:864-868. D0I: 10.1016/j.paid.2009.07.005

Vokey JR, Rendall D, Tangen JM, Parr LA, de Waal FBM. 2004. Visual kin recognition and family resemblance in chimpanzees (Pan troglodytes). J. Comp. Psychol. 118(2):194-199. D0I: 
Vukovic J, Boothroyd LG, Meins E, Burt DM. 2015. Concurrent parent-child relationship quality is associated with an imprinting-like effect in children's facial preferences. Evol. Hum. Behav. 36(4):331-336. D0I: 10.1016/j.evolhumbehav.2015.03.004

401 Walter MJ. 1973. Effects of parental colouration on the mate preference of offspring in the zebra finch, 402 Taeniopygia guttata castanotis Gould. Behaviour 46(1):154-173. D0I: doi:http://dx.doi.org/10.1163/156853973X00229

404 Wilson GD, Barrett PT. 1987. Parental characteristics and partner choice: some evidence for Oedipal 405 imprinting. J. Biosoc. Sci. 19(02):157-161. D0I: doi:10.1017/S0021932000016758

Zei GP, Astolifi P, Jayakar SD. 1981. Correlation between father's age and husband's age: a case of 407 imprinting. J. Biosoc. Sci. 13:409-418. Dol:

408

409 